\title{
O TEMPO E A GESTÃO NA EDUCAÇÃO: ELEMENTOS DE UMA ANÁLISE A PARTIR DA TEORIA CRÍTICA
}

\author{
TIME AND MANAGEMENT IN EDUCATION: ANA ANALISIS \\ THROUGH CRITICAL THEORY
}

Ari Fernando MAIA ${ }^{1}$

RESUMO: Apesar da existência de um vasto campo de estudos sobre a gestão na educação a dimensão temporal praticamente não tem sido discutida, embora seja uma característica pervasiva de qualquer processo pedagógico e uma força organizativa fundamental para a reprodução da sociedade. O objetivo deste artigo é utilizar conceitos elaborados por autores que têm discutido a temporalidade para apontar alguns problemas ainda pouco analisados pelas pesquisas educacionais sob uma perspectiva temporal. A existência de processos de sincronização e dessincronização no cotidiano escolar geram dúvidas e dificuldades que demandam ações de gestão. A análise temporal apresenta desafios tanto ao gestor, que precisa produzir processos de desaceleração significativos, quanto ao educador, que opera no tempo lento e ritualizado das aprendizagens significativas.

PALAVRAS-CHAVE: Teoria crítica e educação. Temporalidade e teoria crítica. Gestão escolar e temporalidade.

ABSTRACT: Despite the existence of a wide field of studies on management in education the temporal dimension has barely been discussed, although it is a pervasive characteristic of any pedagogical process and a fundamental organizational force for the reproduction of society. The purpose of this article is to reflext about concepts of temporality to point out some problems scarcely analyzed by educational research. The existence of processes of synchronization and desynchronization in the school routine generate doubts and difficulties that require management actions. The temporal analysis presents challenges both to the manager, who needs to produce significant deceleration processes, and to the educator, who operates in the slow and ritualized time of meaningful learning.

KEYWORDS: Critical theory and education. Temporality and critical theory. School management and temporality.

\section{Introdução}

Que tipo de contribuições a Teoria Crítica da Sociedade poderia oferecer ao campo da gestão educacional? Com essa questão em pauta procuramos desenvolver

${ }^{1}$ Email: arimaia @ fc.unesp.br 
nesse texto um conjunto de problematizações voltado para o vasto campo da gestão educacional. Nossa base teórica é a chamada Teoria Crítica da Sociedade, também alcunhada, eventualmente, Escola de Frankfurt, que no Brasil tem pautado um amplo leque de reflexões, críticas e proposições metodológicas para a educação, seja a partir da leitura e interpretação de seus fundadores, principalmente Theodor Adorno, Max Horkheimer, Walter Benjamin e Herbert Marcuse, seja a partir de autores brasileiros que se utilizam desse referencial teórico para pensar a educação.

A primeira dificuldade em relação a essa aproximação diz respeito à amplitude de sentidos em que se desdobra a expressão "gestão educacional". O tema da gestão escolar constitui um vasto campo de estudos, abrangendo questões como as políticas globais para a educação (como as do Banco Mundial ou da ONU) e as políticas públicas e parâmetros legais nacionais, até questões diretamente relacionadas ao cotidiano escolar, ao conjunto de parâmetros morais vigentes, ao tipo de visão de mundo que orienta as práticas comuns na escola, ao conjunto de concepções éticas e políticas que dificulta ou facilita o funcionamento dos colegiados escolares, entre outros temas. Este vasto conjunto temático, por sua vez, resulta em objetos de análise, em pesquisas em Educação Escolar, de enorme diversidade, abrangendo o uso de novas tecnologias no âmbito educativo, questões relacionadas à formação continuada dos profissionais ligados mais diretamente à gestão, à sexualidade e ao gênero, à diversidade cultural e suas manifestações no espaço escolar, o significado de democracia e as práticas de gestão etc.

Apesar da imensa dispersão de temas e objetos há alguns parâmetros que são comumente afirmados entre os teóricos que vinculam a educação a um ideal de sociedade democrática e igualitária: admite-se que, com vistas a esse fim, é desejável que a gestão escolar seja democrática e participativa (PARO, 2007). Nesse sentido, é preconizado que a gestão envolva a constituição de colegiados, em condições de autonomia, respeitando suas iniciativas, tendo como referenciais a qualidade do ensino, a utilização ótima dos recursos públicos, a participação ativa de todos os envolvidos e a construção de uma sociedade mais igualitária e democrática. Evidentemente, mesmo autores que preconizam a democracia na escola reconhecem que uma educação democrática, a que desejamos, se configura um ideal, uma utopia, não no sentido de que não seja possível, mas no sentido de que é necessário considerarmos que a própria gestão é uma mediação entre muitas outras e, que sendo a escola contemporânea uma instituição existente numa sociedade capitalista, ou seja, uma sociedade desigual e 
violenta por sua natureza imanente, há sempre dificuldades inusitadas para a consecução de relações plenamente democráticas no contexto escolar. Nesse sentido, a diversidade temática é bem-vinda, já que quanto mais abrangente for o conjunto de mediações analisadas, mais chances teremos de realizar modificações significativas em mediações relevantes para a construção desse ideal.

Mas a contribuição específica da Teoria Crítica da Sociedade impõe uma perspectiva crítica e negativa na análise do objeto. Ou seja, não se trata de elaborar um ideal positivo de como deveria ser a gestão para que a escola se torne democrática, mas de realizar a crítica mais radical possível sobre todas as mediações em que, sob a aparência de liberdade, se reafirma a desigualdade, a violência e a dominação. A ideia de que a educação se volte para a não reprodução da violência que se perpetua na história (ADORNO, 2000) implica um olhar crítico que não recua diante do caráter afirmativo das teorias pedagógicas vigentes. Atualmente, teóricos que procuram atualizar o potencial crítico da primeira geração dos frankfurtianos, têm chamado a atenção para diversas questões relacionadas à velocidade, à constante aceleração da sociedade, a contrapartidas subjetivas deletérias como o déficit de atenção, entre outros temas relacionados à temporalidade, isto é, à experiência humana do tempo.

Nesse sentido, é interessante notar que apesar da imensa diversidade de temas voltados para a questão da gestão escolar, naturalmente relacionados à diversidade de mediações presentes na escola, a questão da temporalidade não tem sido amiúde analisada. $\mathrm{O}$ que visamos neste texto é uma tarefa dupla: primeiramente, argumentar que o tempo é um parâmetro fundamental para a compreensão da sociedade contemporânea, assim como de suas instituições, e apresentar suas características fundamentais de modo a recuperar uma dimensão ética e política suprimida; em segundo lugar, indicar algumas situações em que se torna evidente que a configuração da organização temporal típica de nossa sociedade se reflete em desafios ao campo da educação e, em particular, da gestão escolar.

\section{Definindo criticamente a temporalidade}

Para realizar essa dupla tarefa, utilizaremos conceitos elaborados por três autores: Harmut Rosa, Jonathan Crary e Christoph Türcke, eventualmente recorrendo também a Moishe Postone e Theodor Adorno. Os três primeiros têm em comum uma 
preocupação com uma característica da configuração contemporânea das sociedades capitalistas: sua constante aceleração. Ela se expressa de várias formas, seja no campo cultural, como uma alta compressão de notícias ou imagens em concorrência (TÜRCKE, 2010), seja no âmbito técnico da vida cotidiana, na velocidade dos automóveis, computadores e nos esportes, (ROSA, 2012), seja na emergência de exigências temporais do tipo '24/07', ou seja, vinte e quatro horas por dia sete dias por semana (CRARY, 2014). Compreender o processo de aceleração parece ser importante para identificar certos efeitos nocivos, assim como alguns aspectos da alienação típicos de nossa época.

Essa possibilidade fica clara quando observamos a tese fundamental do livro mais recente de Rosa (2012), “Aceleração e Alienação”, em que ele aponta:

Uma das maneiras de examinar a estrutura e a qualidade de nossas vidas é se concentrar nos motivos temporais. Não somente todos os aspectos da vida podem ser abordados de modo esclarecedor segundo uma perspectiva temporal, mas as estruturas temporais se conectam aos níveis microscópicos e macroscópicos da sociedade, quer dizer, nossas ações e nossas orientações são coordenadas e tornadas compatíveis com os "imperativos sistêmicos" das sociedades capitalistas modernas através de normas, restrições e regulações temporais (p. 8).

É importante ressaltarmos alguns elementos dessa citação: a temporalidade, ou seja, a forma como a sociedade organiza, valoriza e concebe o tempo, o modo como ele é mensurado e organizado, gera normas, cria restrições, impõe regulamentos, em suma, resulta em "imperativos sistêmicos" que atravessam tanto instituições em particular como a sociedade como um todo. Abordar um determinado tema a partir de sua dimensão temporal é esclarecedor justamente porque permite articular de modo significativo os níveis microscópicos - da vida diária, de ações ou instituições específicas -, e macroscópicos - do modo de produção e do processo histórico. A dimensão temporal também permite observar as relações entre os indivíduos e o todo; ela é uma dimensão pervasiva, isto é, que atravessa do início ao fim a totalidade da vida social, articulando ao mesmo tempo o todo e o singular, se conseguirmos identificar sua organização particular em determinada época.

Há ainda mais uma questão fulcral, segundo Rosa (2012), que diz respeito à configuração específica dos imperativos temporais contemporâneos: eles não se articulam eticamente. Segundo Rosa (2012): 
As sociedades modernas são, em meu juízo, reguladas, coordenadas e dominadas por um regime temporal rigoroso e estrito que não é articulado em termos éticos. Os sujeitos modernos podem, então, ser descritos como não sendo restringidos minimamente por regras e sanções éticas, e consequentemente se sentem livres, mas são regidos, dominados e reprimidos por um regime temporal em grande parte invisível, despolitizado, indiscutido, pouco teorizado e inarticulado. Esse regime temporal pode de fato ser analisado graças a um conceito unificador: a lógica da aceleração social (p. 8).

Observando essa tese central de Rosa (2012) podemos depreender que ele chama a atenção para o fato de que a organização temporal subjacente ao funcionamento da sociedade e de suas instituições cria modos de dominação que não são questionados por não serem percebidos como problemáticos, apesar de seus efeitos serem radicais e, eventualmente, notórios. Assim, ele clama por uma análise crítica das normas temporais que organizam, restringem e governam nossas vidas, de modo a possibilitar uma retomada da discussão sobre essas normas num nível ético e político. Em outras palavras, Rosa propõe que é preciso reconhecer que as normas e imperativos temporais são expressões profundamente arraigadas em nosso cotidiano, que atuam de modo abrangente, organizando nossa vida e determinando algumas de suas características fundamentais, mas sem que seja possível compreendermos e discutirmos de fato seu sentido ético e político.

Em geral, nossa atenção se volta para as normas e os regulamentos sistematizados pelas instituições, seus estatutos e leis, até mesmo para as características da moral em determinada sociedade, mas é muito difícil atentar para a dimensão temporal justamente por seu caráter pervasivo e, aparentemente, neutro. De fato, a temporalidade subjaz e atribui sentido a uma experiência histórica, à política, à vida cotidiana de um modo não imediatamente visível. A raiz dessa invisibilidade tem relação com o valor do tempo em uma sociedade capitalista: como só ganha valor, numa sociedade orientada para a produção de mercadorias, aquilo que pode ser vendido como mercadoria mediante sua transformação pelo trabalho assalariado, e como o resultado dessa forma de trabalho é medido - isto é, valorizado - pelo tempo médio para sua realização, o tempo médio de trabalho assalariado, que se pode chamar tempo abstrato, é o critério de toda forma de valorização e substrato material das concepções de temporalidade vigentes (POSTONE, 2014).

Mas o trabalho nas sociedades capitalistas é sempre alienado, ou seja, o trabalhador, tornado ele próprio uma mercadoria, ou vendedor de sua força de trabalho, 
não pode se apossar do produto de seu trabalho, que se torna 'estranho' (entfremde) a ele. Com isso o trabalhador torna-se despossuído não somente do produto de seu trabalho, mas dos meios de sua humanização, estranho à humanidade em sentido genérico e impossibilitado de usufruir das riquezas e benesses que sua própria atividade contribuiu para produzir. Ora, se o tempo coincide com o valor das mercadorias e estas estão estranhadas para o trabalhador, o próprio tempo se torna um elemento alienado. $\mathrm{O}$ valor, objetivação do trabalho abstrato, é idêntico ao tempo abstrato, uma forma particular, determinada, do tempo, num processo social que resulta na abstração da especificidade das atividades humanas e em sua redução a um denominador comum (dinheiro) também correspondente a um tempo abstrato. Assim, não é estranho que o tempo seja uma dimensão tanto pervasiva como invisível, isto é, impossível de ser plenamente dominada enquanto vigorar a forma capitalista de produção.

Esse é o fundamento do problema apontado por Rosa (2012): na lógica da concorrência capitalista toda perda de tempo é uma perda de valor, o que significa que eficiência e velocidade coincidem, e isso se aplica a todas as esferas da vida, constituindo um dos mais notórios imperativos sistêmicos temporais. Extrair o máximo possível da força de trabalho economizando tempo, aumentar a velocidade de todos os processos produtivos e valorizar a performance medida quantitativamente tornam-se valores indiscutidos e estão na base do que Rosa denominou 'aceleração'.

Não obstante, o conceito de aceleração elaborado por Rosa em sua obra mais extensa sobre o tema (ROSA, 2005) considera importantes também as articulações funcionais entre âmbitos sociais distintos. Ele o faz considerando que diferentes âmbitos da sociedade aceleram ou desaceleram em diferentes ritmos, o que cria problemas de sincronização e dessincronização que retomaremos com mais atenção na parte final do texto. Para dar conta da diversidade de âmbitos sociais nos quais pode ocorrer aceleração, desaceleração ou processos temporais paradoxais, Rosa elabora três categorias analíticas: aceleração tecnológica, aceleração da mudança social e aceleração dos ritmos de vida (ROSA, 2012).

A categoria de aceleração técnica identifica o aumento da velocidade de processos técnicos que visam a fins específicos, sendo a forma mais facilmente identificável e mensurável dos processos temporais. O problema é identificar de onde provém a demanda por processos e aparatos técnicos cada vez mais velozes, questão que tem, evidentemente, relação com o vínculo entre tempo e valor já mencionado, mas não somente. Para Rosa (2005) os processos de sincronização e dessincronização em 
cada esfera e entre diferentes esferas e instituições cria uma espiral de aceleração que se retroalimenta. A segunda categoria identifica mudanças em valores, práticas cotidianas, relações, hábitos, atitudes, linguagens etc, e é denominada aceleração da mudança social. É a mais difícil de mensurar e qualificar, porque envolve sempre questões filosóficas e metodológicas delicadas sobre como se identifica a sociedade e como se mede a mudança. A definição de Rosa (2012) lida com essas dificuldades definindo-a como uma 'contração do presente', ou seja, a diminuição da expectativa de que hábitos, valores, atitudes etc sejam válidos em um futuro próximo. Finalmente, a terceira categoria é a aceleração dos ritmos de vida. Trata-se da modalidade de aceleração mais comumente identificada, referindo-se a uma sensação de falta de tempo, à compressão das vivências e ações cotidianas, acompanhada da ânsia ou necessidade de obter mais tempo, ou de produzir mais experiências por unidade de tempo.

A definição conceitual de aceleração, de acordo com Rosa (2012), abarca as relações entre as três categorias, considerando que há uma relativa independência ou, eventualmente, paradoxos temporais envolvendo os três níveis. A aceleração no âmbito das técnicas, por exemplo, deveria produzir mais tempo livre, uma vez que novas tecnologias economizam tempo. Entretanto, se apesar da abundância de novas tecnologias no cotidiano não há mais tempo livre, mas uma sensação de que temos cada vez menos tempo, isso demanda uma explicação. Rosa $(2005$; 2012) afirma que esse paradoxo indica algo fundamental: que a quantidade de operações, ações e tarefas por unidade de tempo aumenta mais rapidamente que a taxa de tempo livre proporcionada pela utilização de novas tecnologias. Para dizer de modo direto: a exploração do trabalho aumenta em uma proporção maior do que a economia de tempo que as tecnologias proporcionam. É desse paradoxo que resulta o conceito de aceleração: entende-se que uma sociedade se encontra em aceleração quando, apesar da aceleração tecnológica, ocorre uma crescente falta de tempo.

A tecnologia, portanto, ocupa uma posição ambígua em relação ao tempo, pois ela simultaneamente produz, potencialmente, mais tempo livre e, por outro lado, ao resolver demandas por mais eficiência temporal, contribui para uma maior velocidade das mudanças sociais e dos ritmos de vida que geram mais aceleração. Efetivamente, há limites para a aceleração, assim como paradoxos e desacelerações, funcionais ou politicamente deliberados. O aumento da velocidade e a disseminação dos automóveis, por exemplo, produz engarrafamentos que tornam o deslocamento em grandes cidades cada vez mais lento; há movimentos como o 'slow food' que questionam a lógica 
temporal típica dos tempos hodiernos. Não obstante, o princípio da competição e da eficiência temporal se impõe em praticamente todas as esferas da vida social, e parece que novas tecnologias são requeridas justamente para que seja possível atender a essa demanda. Uma vez que uma sociedade se engaja em um processo de aceleração, os diversos âmbitos tendem a se retroalimentar, gerando demandas por mais velocidade e eficiência temporal, resultando em condições cada vez mais céleres nos processos tecnológicos, em mudanças mais rápidas em modos de vida e no reconhecimento de que as formas sociais se modificam de modo inexorável.

Ao fim e ao cabo, o contexto geral da aceleração resulta em uma sociedade '24/7' (CRARY, 2014). A expressão, comum em língua inglesa, identifica aquelas atividades que se espera que funcionem o tempo todo, sem interrupção. Na verdade, torna-se um ideal poder operar ininterruptamente. A vida passa a ser considerada boa quando se pode identificá-la a uma atividade contínua, a um acúmulo de vivências, preferencialmente mais e mais intensas, em que a novidade é constante. Mas, se vivenciamos condições de atividade ininterrupta, ao ponto em que o sono e outros ciclos naturais de repetição e interrupção da atividade se veem impedidos, e simultaneamente perdemos todos os referenciais históricos e as possibilidades de pararmos as operações necessárias à reprodução da vida para refletirmos sobre nossa condição, então as condições 24/7 são uma forma contemporânea de imposição totalitária dos imperativos sociais capitalistas aos indivíduos sem que estes se deem conta disso.

Em outras palavras, tornou-se inaudita a distância entre as possibilidades de atuação histórica relevante para os indivíduos e as forças sociais consubstanciadas em formas temporais ubíquas, resultando em uma fratura entre a história da humanidade e as forças que delimitam a vida individual. Segundo Crary (2014):

Há muita pressão para que os indivíduos reimaginem e reconfiguremse a si mesmos, identificando-se com as uniformidades e valores das mercadorias, bem como dos vínculos sociais desmaterializados nos quais estão tão profundamente imersos. A reificação chegou ao ponto de o indivíduo precisar inventar uma concepção de si que otimiza ou viabiliza sua participação em ambientes e velocidades digitais. Paradoxalmente, isso significa assumir um papel inerte e inanimado (p. 109).

O que Crary aponta de forma precisa é que há uma profunda e radical incompatibilidade entre as demandas temporais do capitalismo global impulsionado pela tecnologia digital e as características biológicas e necessidades dos seres humanos 
vivos. A vida biológica é frágil e se constituiu segundo parâmetros temporais 'naturais', isto é, um tempo pautado nos ciclos típicos da história natural, envolvendo dias, estações, anos, eras geológicas e cosmológicas, algo muito diferente da celeridade explosiva da cultura digital. Nesse novo contexto, a vulnerabilidade e a fragilidade de todos os seres naturais, incluindo seres naturais/sociais como nós, humanos, se tornam valores negativos, algo a ser negado e evitado, enquanto se valoriza uma abstrata aceleração sem freios e sem limites, vinculando o melhor ao mais eficaz e veloz. A disposição para o trabalho 24/7 torna-se um valor inescapável, e quem não quiser evitar se tornar irrelevante ou fracassado deve o mais rapidamente possível adotar essa postura.

Evidentemente, esses ideais que negam no ser vivo tudo o que se opõe à celeridade própria do mundo da circulação de mercadorias e da troca resultam em uma negação do sono que o autor utiliza como exemplo da desumanidade dessa lógica. A existência de interlúdios temporais em que o corpo não se deixa utilizar para fins de lucro parece um escândalo, um disparate, algo a ser corrigido mediante a utilização de substâncias - coisa que já se encontra sendo estudada pelo exército norte americano (CRARY, 2014). É isso que está subentendido na própria expressão 24/7, que explicita, na verdade, a pretensão de domínio total sobre a natureza, por meio de uma atividade sem trégua e sem interrupção. Segundo Crary (2014):

O sono é uma interrupção sem concessões no roubo de nosso tempo pelo capitalismo. A maioria das necessidades aparentemente irredutíveis da vida humana - fome, sede, desejo sexual e recentemente a necessidade de amizade - foi transformada em mercadoria ou investimento. $O$ sono afirma a ideia de uma necessidade humana e de um intervalo de tempo que não pode ser colonizado nem submetido a um mecanismo monolítico de lucratividade, e desse modo permanece uma anomalia incongruente e um local de crise no presente global. Apesar de todas as pesquisas científicas, frustra e confunde qualquer estratégia para explorá-lo ou redefini-lo. A verdade chocante, inconcebível, é que nenhum valor pode ser extraído do sono (p. 20).

O que é crucial na citação acima é que se considere o sono um representante singular de um vasto conjunto de necessidades humanas que são administradas de modo a produzir lucros, ou seja, de modo a serem meios para a realização ampliada do capital. $\mathrm{Na}$ verdade, a conclusão da citação, de que nenhum valor pode ser extraído do sono, é só parcialmente verdadeira. Em certo sentido, tira-se partido da perda da possibilidade de dormir, ou das dificuldades cada vez maiores para conciliar o sono, ou da 
necessidade de permanecer acordado por períodos cada vez maiores. Há um significativo número de drogas que se destinam tanto a permitir que o sono seja iniciado e/ou mantido quanto que se permaneça acordado sem as (ainda) inevitáveis falhas cognitivas - de atenção, memória, raciocínio etc - relacionadas à perda de horas ou dias de sono. Como Crary (2014) também aponta, a privação de sono é uma das estratégias fundamentais dos mecanismos de tortura desenvolvidos pelos Estados Unidos na chamada guerra ao terror.

Mas não são somente os que são denominados "terroristas" que são privados de sono. Dorme-se atualmente, em média, duas horas a menos do que no início do século XX, e a progressiva abolição das diferenças entre dia e noite, assim como a onipresença de tecnologias de comunicação que permitem que o trabalhador seja "acessado" a qualquer hora, tornam cada vez mais difícil para qualquer pessoa usufruir de um número suficiente de horas de sono. Ainda segundo Crary (2014):

24/7 é um tempo de indiferença, contra o qual a fragilidade da vida humana é cada vez mais inadequada, e dentro do qual o sono não é necessário nem inevitável. Em relação ao trabalho, torna plausível, até normal, a ideia de trabalhar sem pausa, sem limites. Alinha-se com o inanimado, com o inerte ou com o que não envelhece. Enquanto exortação publicitária, decreta a disponibilidade absoluta e, consequentemente, o caráter incessante das carências e sua incitação, mas igualmente, sua manutenção perpétua (p. 19).

Há dois aspectos da citação que merecem destaque: primeiramente, há uma indiferença do regime temporal capitalista com relação às necessidades humanas, que não são meramente naturais, uma vez que são sempre mediadas pela vida dos homens em uma cultura, mas nem por isso deixam de se manifestar em um corpo que tem carências, que necessita alimento, descanso, abrigo e contato acolhedor de outros seres humanos. Nada disso é possível senão numa temporalidade distinta do tempomercadoria. O segundo aspecto a destacar é que a publicidade exalta a disponibilidade absoluta de serviços e mercadorias como um valor, como algo intrinsecamente desejável, com o que, subrepticiamente, contrabandeia também a ideia de que todos os trabalhadores têm de estar disponíveis o tempo todo.

Em alguma medida essa ideologia se encontra também em expressões como 'sociedade de consumo', que parece uma tentativa de caracterizar a desordem social contemporânea a partir de uma característica do âmbito da circulação de mercadorias e serviços. Na verdade não se pode esquecer que uma parte significativa da população 
mundial não tem sequer o que comer e não consome praticamente nada. Além disso, e talvez mais fundamentalmente, é necessário considerar que mesmo os que consomem em abundância são mobilizados por uma lógica de carência. Como aponta Rosa (2012), incorporamos uma 'fome temporal', isto é, a ideia de que precisamos ver mais coisas, visitar mais lugares, ter mais amores, experimentar mais alimentos, obter mais bens e usufruir mais prazeres. Ora, como a possibilidade de usufruto não é infinita, mas a oferta de supostos prazeres no âmbito da propaganda onipresente faz crer que o número de gozos possíveis é infinito, nos encontramos em uma situação de contínua ampliação da frustração, acompanhada pelo desejo imperioso de obter mais tempo. Um contínuo desejo de obter mais e viver mais intensamente é um elemento essencial da ideologia temporal da modernidade: uma perspectiva hedonista que resulta em uma brutal frustração. Isso coloca num plano histórico e social - se atentamos para a dimensão temporal - os supostamente insaciáveis desejos 'naturais' do homem. Também é importante atentar que, nesse sentido, se desvelam que os supostos poderes da propaganda são somente resultado de uma organização temporal social inconsciente de si mesma.

A sociedade não pode ser caracterizada a partir do consumo, mas pode-se perceber claramente sua tendência a produzir uma cada vez mais intensa "excitação". Türcke (2010) nos chama a atenção para esse fato a partir da mudança na semântica da palavra "sensação", que originalmente designava principalmente percepção e, atualmente, passa a identificar objetos estimulantes, choques de imagens que tem o poder de captar uma atenção cada vez mais fugidia, inconstante, deficitária. Nas palavras de Türcke (2010):

A sociedade moderna se ara como nenhuma sociedade anterior. Seu progresso tecnocientífico minou tudo aquilo que pareceu ser natural: relações estabelecidas de trabalho, de propriedade e patrimoniais, hábitos superados, rituais, fundamentações e crenças, ritmos e extensões de vida comuns, velocidade, formas de pensamento e percepção. Nada é óbvio mais. Somente o inconstante se tornou constante: o estado de uma inquietude geral, de excitação, de efervescência (p. 9).

A principal consequência no âmbito psíquico é o déficit de atenção, que Türcke $(2010 ; 2016)$ interpreta não como uma patologia com origem no sistema nervoso, mas como a expressão psíquica de um limiar histórico, um sintoma em alguns indivíduos de mudanças estruturais na sociedade e no tipo de ambiente que ela oferece aos homens. Tendencialmente, todos tendemos a perder a capacidade de fixar a atenção, de ter uma boa memória, de estabelecer uma relação com os objetos culturais em que eles podem ser revisitados, olhados com delicadeza e em detalhe, decifrados a partir de seus 
indícios. Qualquer pessoa que visite o Museu do Louvre interessado em observar a famigerada Mona Lisa notará que esta é uma tarefa impossível: o quadro se encontra em uma sala lotada de pessoas que se acotovelam para chegar diante dele, virar-se de costas e fazer uma 'selfie'.

A partir desse exemplo, é possível ver que o que Adorno denominava 'semiformação' (ADORNO, 2010, p. 25) - o “espírito conquistado pelo caráter de fetiche da mercadoria" - foi exponencialmente intensificado pela ubiquidade dos aparatos digitais em um contexto de aceleração temporal. A vida sensorial é “adulterada" pela velocidade com que os estímulos são substituídos e pelo contínuo aumento de sua intensidade acompanhado pelo ideal de fazer de si mesmo uma coisa, uma imagem. O ideal de um sujeito autônomo, capaz de pensamento crítico sobre a sociedade e sobre si mesmo, é degradado em um ideal de ajustamento e adaptação a uma ordem social cuja reprodução, sua permanência naquilo que é essencial - as relações de produção -, se faz por meio da mudança célere.

Adorno propunha que a possibilidade de resistir à barbárie depende de sujeitos capazes, justamente, de exercitar a autocrítica e a crítica à ordem social, vinculados a valores culturais relativamente afastados da mera autoconservação e da reprodução da ordem social. A base da constituição desse tipo de sujeito estava no conceito de experiência, um conceito com profundas raízes temporais. Segundo Adorno (2010):

\begin{abstract}
A experiência - a continuidade da consciência em que perdura o ainda não existente e em que o exercício e a associação fundamentam uma tradição no indivíduo - fica substituída por um estado informativo pontual, desconectado, intercambiável e efêmero, e que se sabe que ficará borrado no próximo instante por outras informações. Em lugar do temps durée, conexão de um viver em si relativamente uníssono que desemboca no julgamento, coloca-se um "é assim" sem julgamento, algo parecido à fala dos viajantes que, do trem, dão nomes a todos os lugares pelos quais passam como um raio, a fábrica de rodas ou de cimento, o novo quartel; sempre prontos para dar respostas inconsequentes a qualquer pergunta. A semiformação é uma fraqueza em relação ao tempo, à memória, única mediação capaz de fazer na consciência aquela síntese da experiência que caracterizou a formação cultural em outros tempos (p. 33).
\end{abstract}

Em suma, a sociedade 'excitada', uma cultura que tem entre seus sintomas o déficit de atenção, torna o ideal de formação cultural algo indesejável, e isso se expressa em várias mediações temporais no âmbito da escolarização. A ideia de vincular os sujeitos que estudam a uma tradição cultural perde força e é substituída por ideais relacionados ao seu ajustamento a uma sociedade em constante aceleração. Mas, note-se 
que ajustar pessoas não é exatamente uma prática democrática e, além disso, produzir adaptações a uma sociedade cuja característica mais marcante é o aprofundamento de brutais desigualdades enquanto vigora um regime de aceleração das mudanças em tecnologias, hábitos, valores, ritmos de vida etc, é uma prática autoritária e contraproducente se almejamos uma sociedade mais justa. Nesse sentido, passaremos a discutir de que modo algumas questões temporais precisariam ser cuidadosamente discutidas no âmbito escolar, em especial em relação aos ideais de gestão democrática e participativa.

\section{O tempo da escola}

Já argumentamos que, entre as mediações fundamentais para refletir criticamente sobre as possibilidades de democratizar a instituição escolar, o tempo, embora essencial, não tem sido amiúde analisado. Entendemos, assim, que se torna importante identificar no contexto escolar como os imperativos sistêmicos temporais que a ordem social dissemina se expressam no cotidiano, como eles impactam os ideais de formação cultural, como medeiam o sentido de educação escolar, de democracia na instituição, de gestão compartilhada e colegiada, entre outros.

A primeira questão a assinalar é que a configuração temporal caracterizada pela aceleração constitui-se uma espécie de 'a priori' estrutural que medeia a concepção de mundo, de sociedade e de sujeito para todos os envolvidos com o processo escolar, configurando certa forma de perceber a realidade que, efetivamente, modula o modo como se concebe e valoriza o conhecimento e sua transmissão. A lógica da aceleração da mudança social tende a produzir, ou ao menos a justificar, o abandono de conteúdos, obras de arte e saberes do cânone da cultura ocidental. Efetivamente, não se trata de considerar que tais conteúdos, por si mesmos, sejam emancipatórios, como já argumentou Adorno (2000), mas que não é possível substituir um criterioso juízo sobre a qualidade conceitual, informacional ou estética de determinados conteúdos pelo apelo fugaz da novidade.

Obras de arte, músicas e livros canônicos, para além de sua riqueza técnica, de suas mensagens críticas, da articulação imanente entre forma e conteúdo que os tornam fascinantes, ajudaram a configurar a história de nossa sociedade, contam como nossos antepassados interpretaram em vivenciaram seu momento histórico e, além disso, sobre 
eles há uma imensamente rica fortuna crítica, isto é, muitos já leram e comentaram Dom Quixote, muitos já escutaram e interpretaram Villa Lobos, muitos já assistiram e se fascinaram com os filmes de Glauber Rocha, e assim por diante. O que é canônico tem um acúmulo de história em seu próprio conteúdo, que nunca cessa de ser ampliado pelas interpretações, impressões e leituras feitas por seus interlocutores, ainda que contenham contradições. Privar o processo educativo desse contato com o passado pela leitura aprofundada dessas obras, considerar esse tipo de aprendizado irrelevante, fala muito mais sobre as concepções de escola que embasam as políticas globais e locais do que sobre o valor dessas obras.

Outro aspecto a destacar diz respeito à valorização da performance temporal, de uma concepção de eficiência na utilização dos recursos materiais que somente considera quanto se gasta, em determinado tempo, com cada estudante. Em outras palavras, a aceleração técnica também impacta os conteúdos escolares de forma direta, uma vez que a mais nova tecnologia do âmbito da comunicação passa a ser entendida como a salvação da escola se aplicada em larga escala, em geral substituindo o professor, o texto, a obra, visando baratear e tornar mais eficientes os processos educativos. Em relação a essa questão precisamos considerar pelo menos dois aspectos: o fetiche da técnica é uma ameaça ao potencial esclarecedor que as novas técnicas não deixam de ter, ou seja, na verdade as novas tecnologias poderiam ser muito úteis se não estivessem voltadas exclusivamente para a obtenção de maior eficiência econômica, prejudicando a possibilidade de sua utilização para uma maior eficiência formativa.

De outro lado, é preciso afirmar com todas as letras que os investimentos em educação não podem ser somente vistos quantitativamente, mas deveriam ser avaliados, fundamentalmente, sob uma perspectiva qualitativa, isto é: qual qualidade de educação queremos para as novas gerações? Devemos considerar seriamente que elas terão de lidar com enormes desafios sociais - a brutal desigualdade global -, naturais e ecológicos - o aquecimento global, a extinção de espécies -, e também deverão decidir o que fazer com novas tecnologias, na genética e na inteligência artificial, o que demanda conhecimentos aprofundados e relevantes sobre todos esses temas.

Levantar essa questão implica assumir que precisamos nos posicionar no polo oposto dos que, apesar da aparência de uma defesa da democracia, pensam que a escola deve se ajustar às exigências do mercado. Nesse sentido, a reflexão temporal nos chama a atenção para as forças de sincronização que operam no mercado e que adentram a escola de forma insidiosa. O mercado tende a impor à sociedade, em todas suas 
instituições e mediações, um único valor temporal, o 'tempo monetário', e tende a considerar tabu todas as formas de organização temporal alternativas ou que resistem ao processo de reprodução ampliada do valor sob a forma de aceleração. Mas, como o capitalismo é uma contradição em processo, ele gera simultaneamente uma série de fraturas e dessincronizações temporais. Algumas dessas dessincronizações são freios à aceleração, funcionais ou propositais; constituem fraturas entre as pretensões temporais do mercado e a realidade da vida social e resultam em exclusão, catástrofes humanas e, eventualmente, em movimentos críticos ao capital.

Parece fulcral que se pense em que modelo de temporalidade se fundará a organização - a gestão - da educação: se cedermos aos ideais de aceleração nos parece difícil resistir ao ajustamento da instituição escolar ao modelo de produtividade acelerada. Na contramão, gostaríamos de defender que o tempo das aprendizagens significativas é um tempo lento, que demanda recorrência, contato delicado e tateante com os objetos e conteúdos em pauta, abertura ao diálogo e oferta de um leque amplo de conhecimentos e conteúdos. A escola é uma instituição que deveria visar à formação integral de seres humanos, disponibilizando a eles não somente oportunidades para uma apropriação ampla e integral dos saberes que a humanidade produziu - inclusive dos saberes dos povos oprimidos e da resistência à opressão -, oportunizando a crítica a esses saberes e a seus vínculos com a dominação. A dimensão ética e política do conhecimento deve poder vir à tona, assim como toda a violência e dor que a humanidade, com seu imenso domínio sobre a natureza, ainda perpetra mundo afora.

A própria cultura digital, com suas imagens-choque e sua lógica de 'fluxo total' (JAMESON, 1997) deveria poder ser compreendida e analisada pela escola. Mas, para isso, parece que é essencial que não se utilize filmes, por exemplo, simplesmente reproduzindo o que a cultura mercantilizada faz. O filme precisaria ser compreendido em sua lógica, em sua inserção histórica, buscando obras significativas e críticas, debatendo longamente e retomando a mesma obra várias vezes e focando diferentes mediações. Ora, fazer isso implica uma lógica temporal diferente daquela da aceleração, da sociedade excitada, do 24/7.

A compreensão dos custos pessoais, da dor e da fadiga relacionados à contínua aceleração não parecem ser uma das questões menos importantes a se debater. Mas em relação aos conselhos escolares, onde poderia emergir essa questão, também parece haver problemas de dessincronização. Isso porque o tempo necessário para decidir questões relevantes num plano ético e político é cada vez maior, considerando que 
atualmente todas as questões relevantes nesse campo têm expressão global, envolvem relações complexas entre as nações, uma economia planetária, efeitos futuros da aplicação de novas tecnologias que são sumamente difíceis de prever etc. Mas, quem teria tempo para aprofundar seja a compreensão dessas questões, seja a discussão, que teria de levar em conta várias perspectivas em diálogo, valorizando o melhor argumento? Há uma radical dessincronização entre os temas e a disposição para discutilos. Mesmo temas mais próximos do cotidiano escolar como a diversidade étnica, gênero e sexualidade, o mundo do trabalho etc, se veem ou resumidos e esvaziados, visando fazê-los caber em um tempo curto, ou são adiados para as calendas gregas.

A carga horária de trabalho dos profissionais vinculados à instituição escolar se torna um obstáculo ao seu desenvolvimento pessoal, a um contato mais livre e profundo com objetos culturais, produzindo outra dessincronização relevante. Deveria ser possível a qualquer um que desejasse ser professor administrar com a maior liberdade possível seu tempo de formação, de modo a poder articulá-lo ao seu tempo de trabalho. Efetivamente, essa possibilidade, que somente se considerou relevante para os profissionais docentes da universidade pública, mesmo nesta se encontra em declínio, o que indica a gravidade do que ocorre nos níveis básico e médio.

\section{Considerações finais}

Não se tem a pretensão de abranger todos os temas e objetos de investigação que seria possível analisar a partir da dimensão temporal, mas é viável indicar algumas questões e proposições. A escola é notoriamente perpassada por uma organização temporal: períodos, semestres, grades horárias de disciplinas e atividades pedagógicas, agendas de reuniões, calendários de festas, horários previstos para estudo e reuniões pedagógicas ou de gestão e, finalmente, os próprios currículos, são organizações temporais que ora se ajustam a um tempo acelerado, ora funcionam como resistência ao processo global de aceleração. Caberia refletir e avaliar como é possível à escola produzir dessincronizações significativas, formativas, críticas em relação ao 'tempomonetário’ que predomina amplamente e que força todas as instituições a fazer ajustes temporais visando à aceleração.

Pesquisadores interessados na crítica à temporalidade a partir da Teoria Crítica, focando a área da gestão, poderiam investigar as várias mediações temporais apontadas 
acima, e efetivamente poderiam identificar outras relevantes. Parece ser urgente desnaturalizar a configuração contemporânea da temporalidade, desvelando suas fissuras, contradições e forças de sincronização e dessincronização tal como se apresentam nas políticas educacionais internacionais, nacionais, estaduais e locais. Também parece ser relevante colocar em discussão a impossibilidade de usufruir do tempo necessário para realizar os debates realmente relevantes para a sociedade no ambiente escolar, envolvendo todos os participantes, inclusive aqueles 'dessincronizados', ou seja, aqueles considerados incapazes de contribuir para o debate, como as minorias, os pobres, os negros, as mulheres, os deficientes etc.

O ideal de uma formação cultural crítica só faz sentido se pensado e projetado por meio de uma educação política, que não esconda a desigualdade e o caráter ambivalente da cultura. Esse ideal de formação, ao mesmo tempo valorizaria e ofereceria justamente os conteúdos culturais mais elaborados que o trabalho humano já desenvolveu na história, tornando-a disponível para os estudantes. Também é necessário apontar que a apropriação de conhecimentos relevantes em uma dimensão ética e política só ocorre apropriadamente em um tempo lento, que considere a inserção histórica e social dos saberes e as relações entre passado, presente e futuro que se descortinam quando um conteúdo que está em pauta pode permanecer sendo observado, compreendido, analisado, criticado. Quando a escola acolhe o lento, o demorado e possibilita a pausa, a permanência e a memória, ocorre o cultivo daquelas habilidades tanto desejáveis quanto escassas nesse contexto de aceleração.

Assim, torna-se evidente que não é possível ser conivente com a defesa da aplicação indiscriminada da tecnologia na educação se ela visa, essencialmente, a aceleração proporcionada pela técnica. A mais notória entre as tecnologias que se defende que seja amplamente utilizada na educação é a internet, que de fato permite um ilimitado acesso a conteúdos culturais. Ao alcance da mão encontra-se uma significativa amostra do patrimônio cultural humano. Mas, de que forma os estudantes em formação se utilizam desse potencial? Como os agentes educativos podem utilizar essa disponibilidade de forma realmente útil para a formação? Concordamos com Zuin e Zuin (2011), que é essencial que se proporcione aos estudantes o tempo necessário à reflexão de todos os conteúdos apresentados, por qualquer mídia. Sem esse desdobramento temporal, a mera utilização da tecnologia pode resultar em afirmação inconsciente da lógica da aceleração. 
Parece ser fundamental que todos os conteúdos apresentados aos estudantes possam permanecer um tempo significativo em análise, que permaneçam constantemente presentes e disponíveis, que se repitam e sejam avaliados em suas várias mediações. A tendência atual é que um conteúdo seja escolhido por seu valor de choque, que seja absorvido superficialmente e seja rapidamente esquecido. Frear a tendência à substituição imediata, proporcionar condições para que determinados conteúdos possam ser analisados em minúcia, permitir que temporalidades alternativas se manifestem e estejam presentes no cotidiano escolar, parecem ser critérios temporais relevantes para a atividade pedagógica atualmente. Essa possibilidade implica uma crítica temporal radical no âmbito pedagógico, para todos os agentes do processo, em todos os momentos em que ele ocorre.

Em um sentido amplo, a temporalidade é um elemento absolutamente essencial de qualquer ato aducativo. Educar pressupõe sempre uma decisão sobre o tempo histórico. Sempre precisamos decidir, ao construir um currículo, ao elaborar um calendário escolar, ao preparar uma agenda de eventos e em todas as atividades escolares, que sentido atribuímos ao passado, como identificamos no presente o que consideramos mais relevante discutir agora, e que futuro queremos para os estudantes. Educar, numa perspectiva crítica, pressupõe sempre uma inserção histórica, ou seja, uma decisão sobre como nos relacionamos com o passado, como queremos viver o presente e qual é o futuro que desejamos.

Se essas questões temporais não estão presentes e não são debatidas no cotidiano escolar, nos encontramos numa situação de déficit ético e político. Um gestor que tornasse inevitável o confronto das pessoas envolvidas na escola com esse tipo de questão temporal traria à tona uma dimensão essencial da educação em um sentido crítico.

\section{Referências}

ADORNO, T. W. Educação e Emancipação. São Paulo: Ed. Ática, 2000.

ADORNO, T. W. Teoria da Semiformação. In: PUCCI, B et al. (orgs) Teoria Crítica e Inconformismo. Campinas: Autores Associados, 2010

CRARY, J. 24/7. Capitalismo Tardio e os Fins do Sono. São Paulo: Cosac Naify, 2014. 
JAMESON, F. Pós-modernidade: a lógica cultural do capitalismo tardio. São Paulo: Ed. Ática, 1997.

PARO, V. H. Gestão Escolar, Democracia e Qualidade do Ensino. São Paulo: Ed. Ática, 2007.

POSTONE, M. Tempo, Trabalho e Dominação Social: uma reinterpretação da teoria crítica de Marx. São Paulo: Boitempo, 2014.

ROSA, H. Accélération: une critique sociale tu temps. Paris: La Découverte, 2005.

ROSA, H. Aliénation et Accélération: vers une théorie critique de la modernité tardive. Paris: La Découverte, 2012.

TÜRCKE, C. Sociedade Excitada: filosofia da sensação. Campinas, SP: Editora da Unicamp, 2010.

TÜRCKE, C. Hiperativos: abaixo a cultura do déficit de atenção. Rio de Janeiro: Paz e Terra, 2016.

ZUIN, V. G; ZUIN, A. A. S. Memória, Internet e Aprendizagem Turbo. Currículo sem Fronteiras, v. 11, n.2, pp 221-239, jul/dez 2011.

\section{Como referenciar este artigo}

MAIA, Ari Fernando . O tempo e a gestão na educação: elementos de uma análise a partir da teoria crítica. Revista on line de Política e Gestão Educacional, Araraquara, v.20, n.3, p. 528-546, $2016 . \quad$ Disponível em: <http://dx.doi.org/10.22633/rpge.v20.n3.9758>. ISSN: 1519-9029.

Submetido em: outubro/2016

Aprovado em: novembro/2016 